\title{
Nuevas Tendencias en Agricultura de la Región Andina
}

\section{J Selva Andina Biosph. 2016; 4(1):1-2.}

La agricultura convencional actual presenta una serie de impactos negativos para el medio ambiente y la salud de los seres humanos, ocasionados por el inadecuado uso de agro tóxicos, cuyos principios activos de algunos de ellos son cancerígenos, mutagénicos y además, suelen perdurar en el suelo y el agua por varios años hasta que se degraden completamente, acumulándose por bioconcentración en los distintos eslabones de la cadena alimenticia.

La FAO manifiesta que, los plaguicidas son resultado del antiguo anhelo del ser humano por librarse de las plagas que invaden su modo de vida. Pero en el mundo moderno ya es conocida la otra cara de algunas de estas sustancias: son venenos peligrosos para la salud y el ambiente, en el cual se plantea la responsabilidad de los gobiernos en la regulación de estas sustancias, la necesidad de ayudar a los países con dificultades técnicas para asumir los riesgos de su utilización y, la importancia de contar con buenas prácticas de producción y comercio.

Con la creciente demanda de plaguicidas, se incrementaron significativamente los accidentes y las enfermedades asociadas. Según datos de la Organización Mundial de la Salud, anualmente se intoxican dos millones de personas por exposición directa o indirecta a plaguicidas. De este total, el $75 \%$ pertenece a países en vías de desarrollo, donde se utiliza el 25\% de la producción mundial de los plaguicidas.

Ante esta realidad es necesario introducir innovaciones y prácticas agroecológicas en la agricultura. Entre estas prácticas el uso de enemigos naturales como: depredadores, parasitoides o entomopatógenos es una de las prácticas de mayor aceptación entre los agricultores debido a su gran aporte en el manejo de poblaciones de plagas y enfermedades (MIPE) en los cultivos. Sin embargo, más recientemente, la utilización de microorganismos benéficos también ha ofrecido algunas soluciones en la agricultura, siendo entre las más notables el uso de especies de microorganismos benéficos para el mejoramiento del estado nutricional de los suelos cultivables y, por otro lado, microorganismos, tales como Trichoderma spp, el cual ha sido señalado como inductor de resistencia en especies de plantas asociadas. Estos hallazgos han abierto una ventana de posibilidades de manejo de la actividad productiva del campo, sin embargo, para su implementación se hace necesario generar un pensamiento crítico en relación al modelo de agricultura predominante que promueve la industria del agro negocio, además de demandar que las instituciones de investigación desarrollen biotecnologías que sean de fácil manejo y accesibles a la economía de los pequeños y medianos agricultores.

Este cambio de pensamiento involucra el compromiso de los investigadores, así como alianzas entre organizaciones de productores, consumidores, gobiernos locales que reorienten los sistemas de producción 


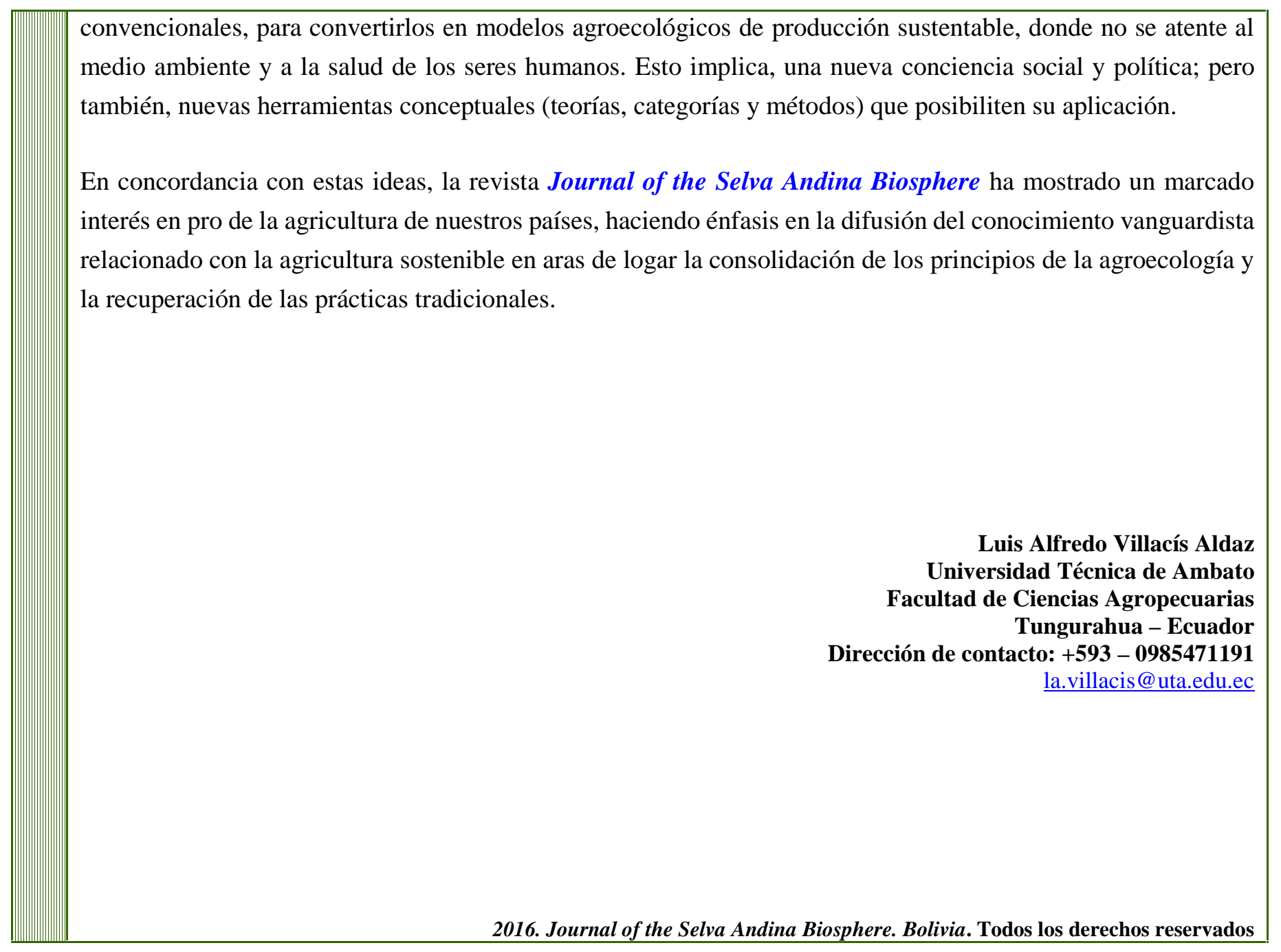

